\title{
Chemical-defined medium supporting the expansion of human mesenchymal stem cells
}

\author{
Jianyong $\mathrm{Xu}^{1 *}$, Wei Lian${ }^{1}$, Jieting Chen², Wenlei $\mathrm{Li}^{3}$, Lingyun $\mathrm{Li}^{1}$ and Zhong Huang ${ }^{1}$
}

\begin{abstract}
Objectives: Mesenchymal stem cells (MSCs) have been intensively investigated as to their therapeutic potentials. However, the full chemical-defined medium supporting the isolation and expansion of human MSCs has not been developed yet.

Materials and methods: Here, we developed the full chemical-defined medium, NBVbe medium, via RNA sequencing, bioinformatic analysis, and growth factor screening.

Results: The NBVbe medium contains N2B27 medium with the BSA (bovine serum albumin) replaced by the recombinant human albumin, bFGF (basic fibroblast growth factor), vitamin C, and EGF (epidermal growth factor). The NBVbe medium could support the isolation and expansion of human MSCs from the umbilical cords.

Conclusions: The full chemical-defined medium supporting the isolation and expansion of human MSCs has been developed. This would be helpful for further optimization of the MSC medium, their clinical applications, and molecular characterization.
\end{abstract}

Keywords: Mesenchymal stem cells, MSCs, Chemical-defined medium, NBVbe medium

\section{Introduction}

Mesenchymal stem cells (MSCs) are widely investigated because of their therapeutic potentials. In addition to their abilities to differentiate into multiple cell types, they could orchestrate the immune responses and modulate the tissue microenvironment, resulting in tissue regeneration [1-6]. Their supportive roles in regulating hematopoietic stem cell (HSC) homeostasis also highlight their therapeutic applications in HSC transplantations $[7,8]$.

Despite the intensive studies on their therapeutic applications, many basic questions remain unsolved,

\footnotetext{
* Correspondence: xujianyong@szu.edu.cn

'Guangdong Provincial Key Laboratory of Regional Immunity and Diseases, Department of Immunology, School of Medicine, Shenzhen University,

Nanhai Avenue 3688, Shenzhen 518060, Guangdong, People's Republic of China

Full list of author information is available at the end of the article
}

such as the cell identity and origin. Differing from other types of adult stem cells, MSCs could be isolated from many tissues, such as the bone marrow, adipose, and umbilical cord $[1,7]$. Whether they have the same origin and function remains unclear. Furthermore, their specific cell surface markers have not been developed so far [9]. Indeed, their definition, function, and therapeutic effects need to be delineated precisely [10].

One of the major obstacles to solving these basic questions is that the full chemical-defined medium supporting the expansion of human MSCs is missing. It has been demonstrated that the human serum and platelet lysate (PL) could support the human MSCs' expansion in vitro $[11,12]$. And the human platelet lysate has been used as the standard culture medium for MSCs' clinical applications [13, 14]. However, the

(c) The Author(s). 2020 Open Access This article is licensed under a Creative Commons Attribution 4.0 International License, which permits use, sharing, adaptation, distribution and reproduction in any medium or format, as long as you give appropriate credit to the original author(s) and the source, provide a link to the Creative Commons licence, and indicate if changes were made. The images or other third party material in this article are included in the article's Creative Commons licence, unless indicated otherwise in a credit line to the material. If material is not included in the article's Creative Commons licence and your intended use is not permitted by statutory regulation or exceeds the permitted use, you will need to obtain permission directly from the copyright holder. To view a copy of this licence, visit http://creativecommons.org/licenses/by/4.0/ The Creative Commons Public Domain Dedication waiver (http://creativecommons.org/publicdomain/zero/1.0/) applies to the data made available in this article, unless otherwise stated in a credit line to the data. 
batch variation of human PL preparation affects the phenotype and function of MSCs [15, 16]. Furthermore, the human platelet has limited resources. Thus, developing a full chemical-defined medium for human MSCs is critical for both basic biology study and also the clinical applications.

To overcome the inconsistent performance associated with the human platelet lysate, lots of efforts have been made to uncover the critical components of the platelet lysate which supports the MSCs' expansion [17-24]. Unfortunately, it remains largely unclear what constituents mainly contribute to the MSCs' proliferation. Here, we would provide an alternative strategy to uncover those critical factors for supporting MSCs' expansion. And finally, we established the full chemical-defined medium supporting the isolation and expansion of the human MSCs.

\section{Materials and methods}

Isolation and expansion of human MSCs with serumbased medium

This study was approved by the ethics committee of Shenzhen University and followed the tenants of the Declaration of Helsinki. The human umbilical cords were collected in $10 \mathrm{~min}$ after the baby's birth and the informed consents were obtained. The umbilical cords were stored in DMEM/High Glucose (Gibco, USA) with antibiotics (500 units $/ \mathrm{mL}$ of penicillin and $500 \mu \mathrm{g} / \mathrm{mL}$ of streptomycin) on ice and delivered to the lab. They were minced into $1-3 \mathrm{~mm}^{3}$ fragments immediately and incubated in $1 \mathrm{mg} / \mathrm{mL}$ collagenase B (STEMCELL Technologies, diluted in DMEM/High Glucose) for $12 \mathrm{~h}$ at $37^{\circ} \mathrm{C}$. Then the isolated single cells of human MSCs were expanded in DMEM/High Glucose (Gibco, USA) plus 10\% human serum (purified from the umbilical cord blood), $10 \mathrm{ng} / \mathrm{mL}$ bFGF (basic fibroblast growth factor, Peprotech), $50 \mu \mathrm{g} / \mathrm{mL}$ vitamin C (Sigma), and antibiotics (100 units $/ \mathrm{mL}$ of penicillin and $100 \mu \mathrm{g} / \mathrm{mL}$ of streptomycin). The human MSCs were passaged with TrypLE (Thermo Scientific).

\section{Sample treatment and RNA sequencing}

Human MSCs at passage 2 were plated onto p6 plates at the concentration of $5 \times 10^{4}$ cells per well. Then they were incubated with DMEM/High Glucose (Thermo Scientific), $1 \%$ platelet lysate (Merk) in DMEM/High Glucose (Thermo Scientific) plus $2 \mathrm{U} / \mathrm{mL}$ heparin (Sigma), $2 \%$ platelet lysate in DMEM/High Glucose plus $2 \mathrm{U} / \mathrm{mL}$ heparin, or $5 \%$ platelet lysate in DMEM/High Glucose plus $2 \mathrm{U} / \mathrm{mL}$ heparin for 5 days. The RNA was extracted with Eastep ${ }^{\circ}$ Super Total RNA Extraction Kit (Promega). The quality control, library construction, RNA sequencing, and bioinformatic analysis were performed in BGI
(Beijing Genomics Institute). The PCA (principal component analysis) was performed by princomp and ggplot2 packages in R. The KEGG (Kyoto Encyclopedia of Genes and Genomes) pathway analysis was performed by phyper in $\mathrm{R}$. The protein-protein interaction analysis was conducted by DIAMOND and STRING. The expression pattern analysis was performed by Mfuzz package in R. All the analyses were conducted with the online bioinformatic platform Dr. Tom (biosys.bgi.com/) provided by BGI.

\section{Medium components screening}

For basal medium screening, the human MSCs at passage 2 were plated onto 12 plates at the concentration of $2 \times 10^{4}$ cells per well. Then they were incubated with indicated mediums for 5 days and the cell counted with hemocytometer. The medium was refreshed every 2 days. The DMEM medium was DMEM/High Glucose (Thermo Scientific). The FBS medium was composed of DMEM/High Glucose plus 10\% FBS (fetal bovine serum, Thermo Scientific). The N2B27 medium was composed of DMEM/High Glucose plus N2 (Thermo Scientific) and B27 (Thermo Scientific). The N2B27-VA medium was composed of DMEM/High Glucose plus N2 (Thermo Scientific) and B27 without vitamin A (Thermo Scientific). The NB medium was composed of DMEM/ High Glucose plus NB mixture (Table 1). The 5\% PL medium was composed of DMEM/High Glucose plus $5 \%$ platelet lysate (Merk) and $2 \mathrm{U} / \mathrm{mL}$ heparin (Sigma).

Table 1 Composition of the NB medium $(\times 50)$

\begin{tabular}{ll}
\hline Biotin & $125 \mu \mathrm{g} / \mathrm{mL}$ \\
DL-alpha-tocopherol acetate & $50 \mu \mathrm{g} / \mathrm{mL}$ \\
DL-alpha-tocopherol & $50 \mu \mathrm{g} / \mathrm{mL}$ \\
Human recombinant albumin & $2 \mathrm{mg} / \mathrm{mL}$ \\
Catalase & $125 \mu \mathrm{g} / \mathrm{mL}$ \\
Human recombinant insulin & $410 \mu \mathrm{g} / \mathrm{mL}$ \\
Human transferrin (Holo) & $5 \mathrm{mg} / \mathrm{mL}$ \\
Superoxide dismutase & $375 \mathrm{U} / \mathrm{mL}$ \\
Corticosterone & $1 \mu \mathrm{g} / \mathrm{mL}$ \\
D-Galactose & $750 \mu \mathrm{g} / \mathrm{mL}$ \\
Ethanolamine & $0.05 \mu \mathrm{L} / \mathrm{mL}$ \\
Glutathione (reduced) & $50 \mu \mathrm{g} / \mathrm{mL}$ \\
L-Carnitine & $100 \mu \mathrm{g} / \mathrm{mL}$ \\
Linoleic acid & $50 \mu \mathrm{g} / \mathrm{mL}$ \\
Linolenic acid & $50 \mu \mathrm{g} / \mathrm{mL}$ \\
Progesterone & $640 \mathrm{ng} / \mathrm{mL}$ \\
Putrescine & $1.61 \mathrm{mg} / \mathrm{mL}$ \\
Sodium selenite & $900 \mathrm{ng} / \mathrm{mL}$ \\
T3 (triodo-l-thyronine) & $100 \mathrm{ng} / \mathrm{mL}$ \\
\hline
\end{tabular}


For growth factor or chemical screening, the human MSCs at passage 2 were plated onto p12 plates at the concentration of $2 \times 10^{4}$ cells per well. The growth factors or chemicals were added into the NB medium and incubated the cells for 5 days. The medium was refreshed every 2 days. The concentration was used as $2 \mu \mathrm{M}$ for BIO (6-bromoindirubin-3'-oxime), $50 \mu \mathrm{g} / \mathrm{mL}$ for Vc (vitamin C), $10 \mathrm{ng} / \mathrm{mL}$ for OSM (oncostatin $\mathrm{M}$ ), PDGF (platelet-derived growth factor)-AA, PDGF-AB, PDGF-BB, bFGF, HGF (hepatocyte growth factor), EGF (epidermal growth factor), IGF (insulin-like growth factor), BDNF (brain-derived neurotrophic factor), NGF (nerve growth factor), VEGFA (vascular endothelial growth factor A), TGF $\beta 2$ (transforming growth factor beta 2), IL (interleukin)-1 $\beta$, IL-6, IL-7, CSF2 (colonystimulating factor 2), CXCL1 (C-X-C motif chemokine ligand 1), CXCL2, CXCL5, CXCL6, CXCL8, CXCL10, CXCL12, CCL2 (C-C motif chemokine ligand 2), CCL7, CCL11, and CCL20 (all from Peprotech).

\section{Cell doubling time assessment}

The human MSCs at passage 2 were plated onto $\mathrm{p} 6$ plates at the concentration of $5 \times 10^{4}$ cells per well. Then they were incubated with FBS medium (DMEM/High Glucose plus 10\% FBS), 5\% PL medium (DMEM/High Glucose plus $5 \%$ platelet lysate and $2 \mathrm{U} / \mathrm{mL}$ heparin), or NBVbe medium (DMEM/High Glucose plus NB, $50 \mu \mathrm{g} / \mathrm{mL} \mathrm{Vc}$, $10 \mathrm{ng} / \mathrm{mL}$ bFGF and $10 \mathrm{ng} / \mathrm{mL}$ EGF), as separate parallel experiments. Cells were passaged with TrypLE when they reached $80-90 \%$ confluence and replated with $5 \times 10^{4}$ cells per well in p6 plate for continuous expansion.

\section{Flow cytometry}

The human MSCs, expanded with the NBVbe medium, were dissociated with TrypLE and re-suspended in PBS containing 5\% BSA (bovine serum albumin, Sigma). They were incubated with the mouse anti-human antibody CD90-FITC, CD73-FITC, CD105-FITC, HLADR-FITC, CD45-FITC, CD34-FITC, CD19-FITC, CD11b-FITC, or IgG-FITC (all from BD Biosciences) for $30 \mathrm{~min}$. Cells were analyzed with the BD ACCURI C6 PLUS machine after being washed with PBS two times. The data were further analyzed with the Flowjo software.

\section{Colony formation assay}

The human MSCs were dissociated with TrypLE and diluted with the $5 \% \mathrm{PL}$ or NBVbe medium at the concentration of $1 \times 10^{4}$ cell $/ \mathrm{mL}$. Then the hanging drops were performed on non-adhesive petri-dishes with $20 \mu \mathrm{L}$ per drop. Six hours later, the 5\% PL or NBVbe medium was added to the dish and cultured for 7 days. Then the colonies were plated onto $0.1 \%$ gelatin-coated dishes for 1 day and stained with crystal violet solution $(0.05 \%$ crystal violet, $1 \%$ formaldehyde, and $1 \%$ methanol in $\mathrm{PBS}$ ) for $20 \mathrm{~min}$.

\section{Human MSC differentiation and characterization}

The human MSC differentiation and characterization were conducted with $\mathrm{StemPro}^{\circ}$ Adipogenesis Differentiation Kit (Gibco), StemPro Osteogenesis Differentiation Kit (Gibco), StemPro ${ }^{\circ}$ Chondrogenesis Differentiation Kit (Gibco), and Human Mesenchymal Stem Cell Functional Identification Kit (R\&D Systems), according to the instructions.

\section{Isolation and expansion of human MSCs with the NBVbe medium}

The human umbilical cords were collected in $10 \mathrm{~min}$ after the baby's birth and the informed consents were obtained. The umbilical cords were stored in DMEM/ High Glucose (Gibco, USA) with antibiotics (500 units/ $\mathrm{mL}$ of penicillin and $500 \mu \mathrm{g} / \mathrm{mL}$ of streptomycin) on ice and delivered to the lab. They were minced into 1-3 $\mathrm{mm}^{3}$ fragments immediately and incubated with indicated dissociation reagents according to the instructions. The dissociation reagents include TrypLE (Gibco), 0.05\% Trypsin-EDTA (Gibco), Accutase (STEMCELL Technologies), GCD (Gentle Cell Dissociation Reagent, STEMCELL Technologies), SR (ReLeSR ${ }^{\mathrm{m}}$, STEMCELL Technologies), CDB (Cell Dissociation Buffer, enzymefree, Gibco), ACF (Animal Component-Free Cell Dissociation Kit, STEMCELL Technologies), Collagenase B (STEMCELL Technologies, diluted in DMEM/High Glucose), and DNase I (Sigma), Dispase II (Sigma). Then the isolated single cells of human MSCs were expanded in the NBVbe medium (DMEM/High Glucose plus NB, $50 \mu \mathrm{g} / \mathrm{mL}$ Vc, $10 \mathrm{ng} / \mathrm{mL}$ bFGF, and $10 \mathrm{ng} / \mathrm{mL}$ EGF). The human MSCs were expanded with TrypLE (Thermo Scientific).

\section{Statistical analysis}

Data were analyzed using SPSS software for Windows (SPSS Inc.) and are shown as mean \pm SEM (standard error of the mean). Student's $t$ test was used for twogroup comparison and 1-way ANOVA for multiplegroup comparison with normal data distribution, parametric test, and Tukey's post hoc tests. A level of $P<0.05$ was considered statistically significant.

\section{Results and discussion}

Lots of efforts have been made to uncover the critical components of the platelet lysate for supporting the MSCs' expansion [17-24]. Unfortunately, it remains largely unclear what constituents mainly contribute to the MSCs' proliferation. To develop the full chemicaldefined medium for supporting the proliferation of human MSCs, we investigated the critical regulators, 
which are responsible for the MSCs' proliferation, through analyzing the responses of the MSCs to the platelet lysate via RNA sequencing and bioinformatic analysis, instead of analyzing the platelet lysate itself. Therefore, the transcriptome of the MSCs was analyzed after exposing to different concentrations of human platelet lysate.

The human platelet lysate had the dose effects on the proliferation of human MSCs (Fig. 1a). The PCA showed that the human MSCs treated with $1 \%$ and $2 \%$ platelet lysate had similar gene expression patterns while the $5 \%$ platelet lysate conferred human MSCs as a very different pattern (Fig. 1b). Therefore, the signal pathways or important genes responsible for human MSC proliferation should also have the dose effects. Gene expression pattern clustering among the samples treated without human platelet (negative control (NC)) or with different concentrations of human platelet lysate (1\%, $2 \%$, and $5 \%$ PL) was performed (Supplementary Fig. 1). Both upregulation and downregulation patterns were further analyzed, because the key components of the platelet lysate might have the positive regulations or negative feedback regulations on the gene expression of MSCs. Thus, the KEGG pathway enrichment analysis was performed for genes from clusters 2, 3, 5, 7, 8, 9, and 11 (Fig. 1c, Supplementary Fig. 2). Among all these important pathways activated or suppressed by the human PL, the MAPK (mitogen-activated protein kinase) signal pathway was further studied as it has been demonstrated as one key pathway for cell proliferation [25]. Protein-protein interaction network analysis showed that a panel of important growth factors or receptors was involved in the MAPK pathways which might contribute to the supportive role of PL for human MSC proliferation (Fig. 1d).

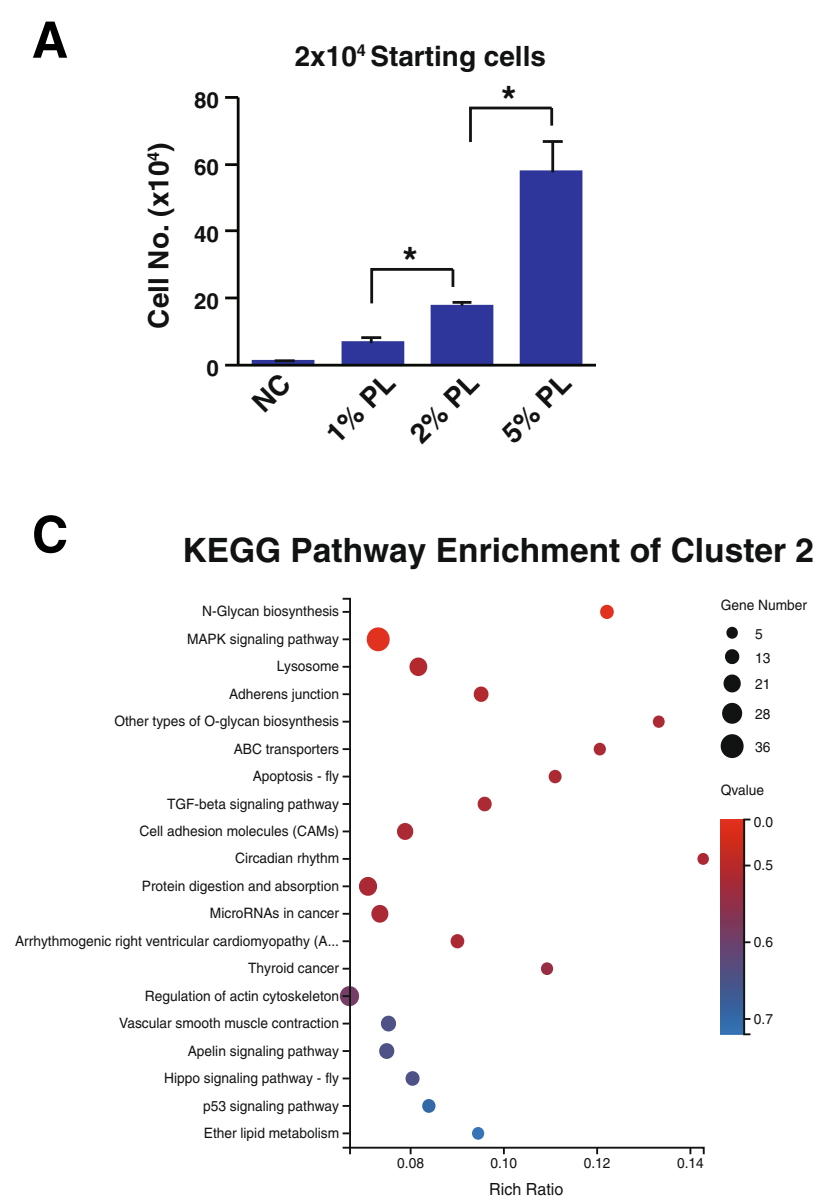

B

PCA

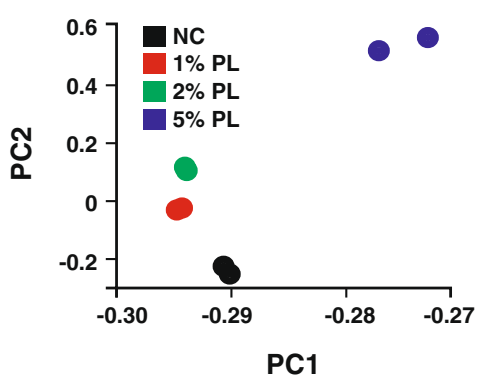

D

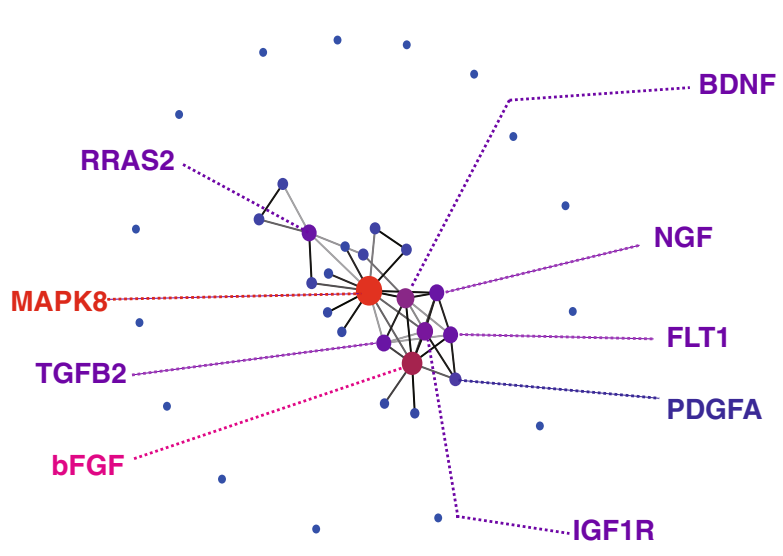

Fig. 1 Transcriptome analysis of the human MSCs exposed to different concentrations of human platelet lysate. a Cell number counting after human MSCs exposed to 1\%,2\%, and 5\% PL in DMEM. Cells were plated onto p12 plates at $2 \times 10^{4}$ cells per well and the cell number was counted 5 days later. $\mathbf{b}$ PCA of human MSCs exposed to different concentrations of human platelet lysate. $\mathbf{c}$ KEGG pathway enrichment of cluster 2 derived from the gene expression pattern clustering analysis. $\mathbf{d}$ Protein-protein interaction analysis of the genes derived from the MAPK signaling pathway of cluster 2. NC, negative control, Dulbecco's modified Eagle's medium-high glucose; PL, human platelet lysate; An asterisk indicates $P<0.05$ 
To analyze these potential important growth factors uncovered from the RNA-sequencing analysis, several basic mediums were firstly tested. Ideally, the basic medium should support the human MSCs alive or proliferation and also have the potential to develop as a full chemical-defined medium. The N2B27 medium is a serum-free medium suitable for neural stem cell and pluripotent stem cell proliferation [26, 27]. Thus, two types of N2B27 were compared, with or without vitamin A. Data showed that the N2B27-VA (N2B27 without vitamin A) could support the human MSC proliferation, much better than the N2B27 with vitamin A or FBS (fetal bovine serum) (Fig. 2a). Although the recipe of commercial N2B27 is unavailable to the public, the more original recipe and modified version of N2B27 had been published $[28,29]$. Then the BSA (bovine serum albumin) component of the N2B27-VA was replaced by recombinant human albumin, termed as the NB medium (Table 1). Data showed that the NB medium was comparable to the N2B27-VA medium (Fig. 2A). Then 12 growth factors uncovered from the RNA-sequencing analysis were added to the NB medium to assess whether they could support the human MSC proliferation. Furthermore, we also tested two factors, BIO (6bromoindirubin-3'-oxime, the GSK3 $\beta$ inhibitor) and OSM (oncostatin $\mathrm{M}$ ) that were used for cardiac progenitor derivation which also expresses CD105 [30]. Totally, 14 growth factors or chemicals were evaluated. Among them, the $\mathrm{Vc}_{\mathrm{C}}$ (vitamin C), PDGF-AB (platelet-derived growth factor $\mathrm{AB}$ ), bFGF (basic fibroblast growth factor), and EGF (epidermal growth factor) showed beneficial effects on MSC proliferation while BIO, OSM, and PDGF-

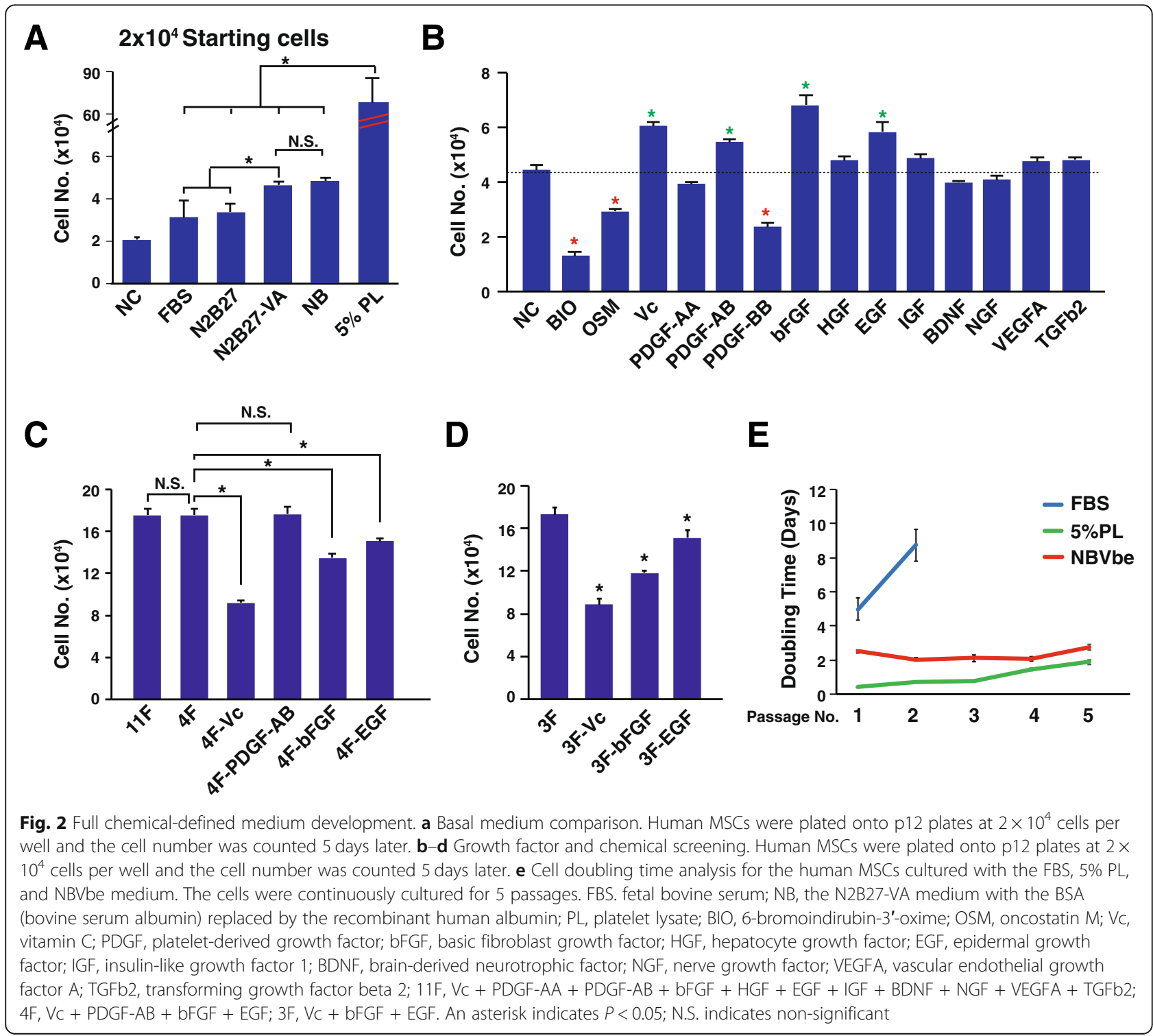


BB significantly suppressed their expansion (Fig. 2b). The four-factor combination (4F), including Vc, PDGF$\mathrm{AB}, \mathrm{bFGF}$, and EGF, showed similar beneficial effects on MSC proliferation when compared with combining them together (the eleven-factor combination, excluding BIO, OSM, and PDGF-BB, 11F) (Fig. 2c). And further eliminating the PDGF-AB did not affect the MSCs proliferation while eliminating the Vc, bFGF or EGF significantly suppressed their proliferation (Fig. 2c). Thus, the 3F (3 basic factors), including Vc, bFGF, and EGF, is the minimal combination for supporting the human MSCs' expansion, as eliminating anyone of them could
A
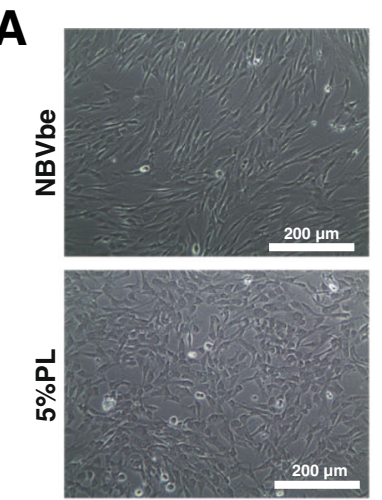

C
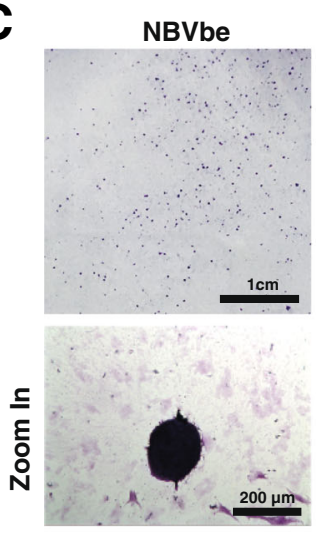

E

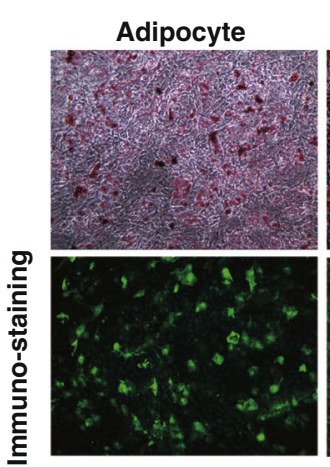

B

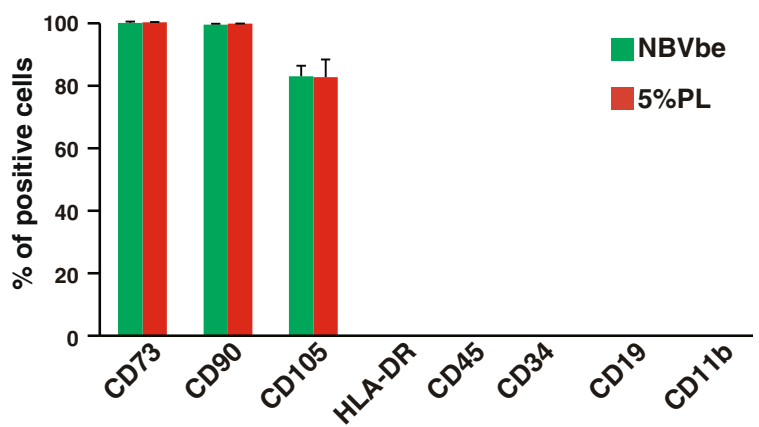

D

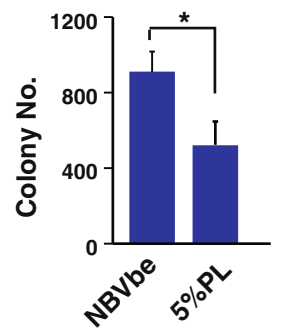

$5 \% \mathrm{PL}$

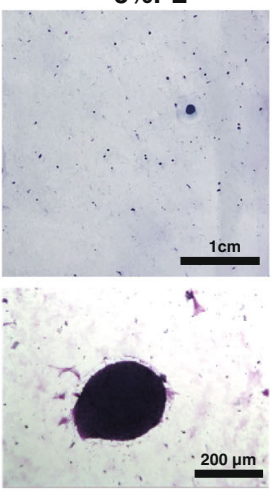

Osteocyte

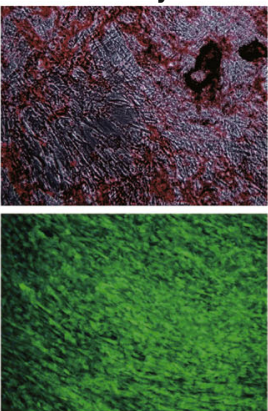

Chondrocyte

Fig. 3 Characterization of human MSCs cultured with the NBVbe medium. a The human MSCs cultured with NBVbe medium had the different cell morphology from them cultured with the $5 \%$ PL medium. Scale bar, $100 \mu \mathrm{m}$. b Cell surface marker analysis by flow cytometry. c Colony formation assay for human MSCS cultured with the NBVbe medium or 5\% PL medium. Scale bar for the upper panel, $1 \mathrm{~cm}$. Scale bar for the lower panel, $200 \mathrm{\mu m}$. d Colony number counting for human MSCs cultured with the NBVbe medium or 5\% PL medium for 5 passages. e The human MSCs were directed to adipocytes, osteocytes, and chondrocytes after cultured with the NBVbe medium for 5 passages. Left: Oil Red O staining and anti-FABP4 immuno-staining for the differentiated adipocytes; middle: Alizarin Red S staining and anti-Osteocalcin immunostaining for the differentiated osteocytes; right: Alcian blue staining and anti-Aggrecan immunostaining for the differentiated chondrocytes. Scale bar, $200 \mu \mathrm{m}$. An asterisk indicates $P<0.05$ 
significantly inhibit the cell proliferation (Fig. 2d). Although the $\mathrm{NB}$ medium plus $3 \mathrm{~F}$, termed as the NBVbe medium, had longer doubling time than the $5 \%$ PL, it was much better than the FBS-based medium (Fig. 2e).
To further confirm that the NBVbe medium could really support the expansion of human MSCs, human MSCs were characterized after cultured with the NBVbe medium for 5 passages. They showed more fibroblastlike morphology (Fig. 3a) and were positive for MSC cell

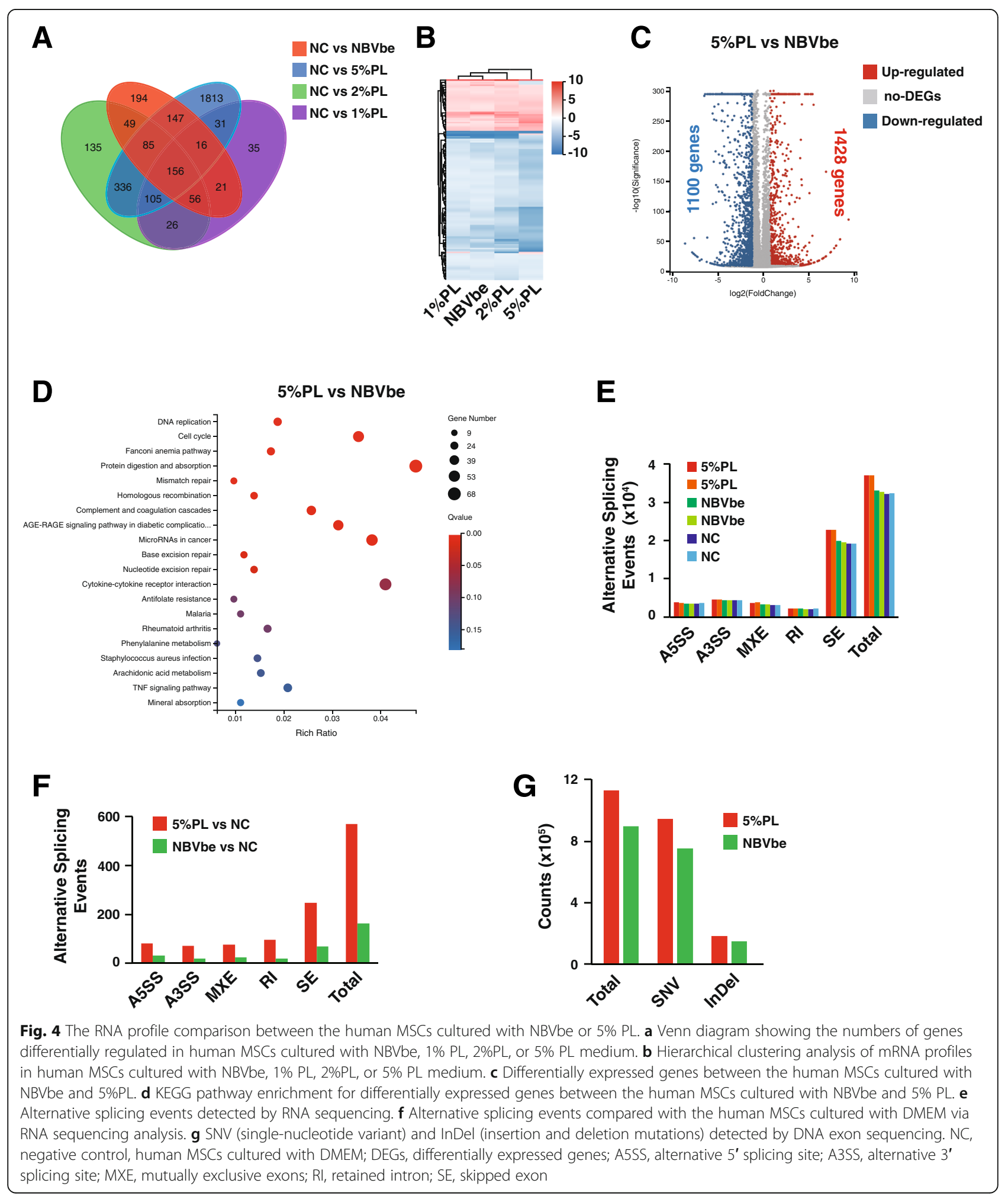




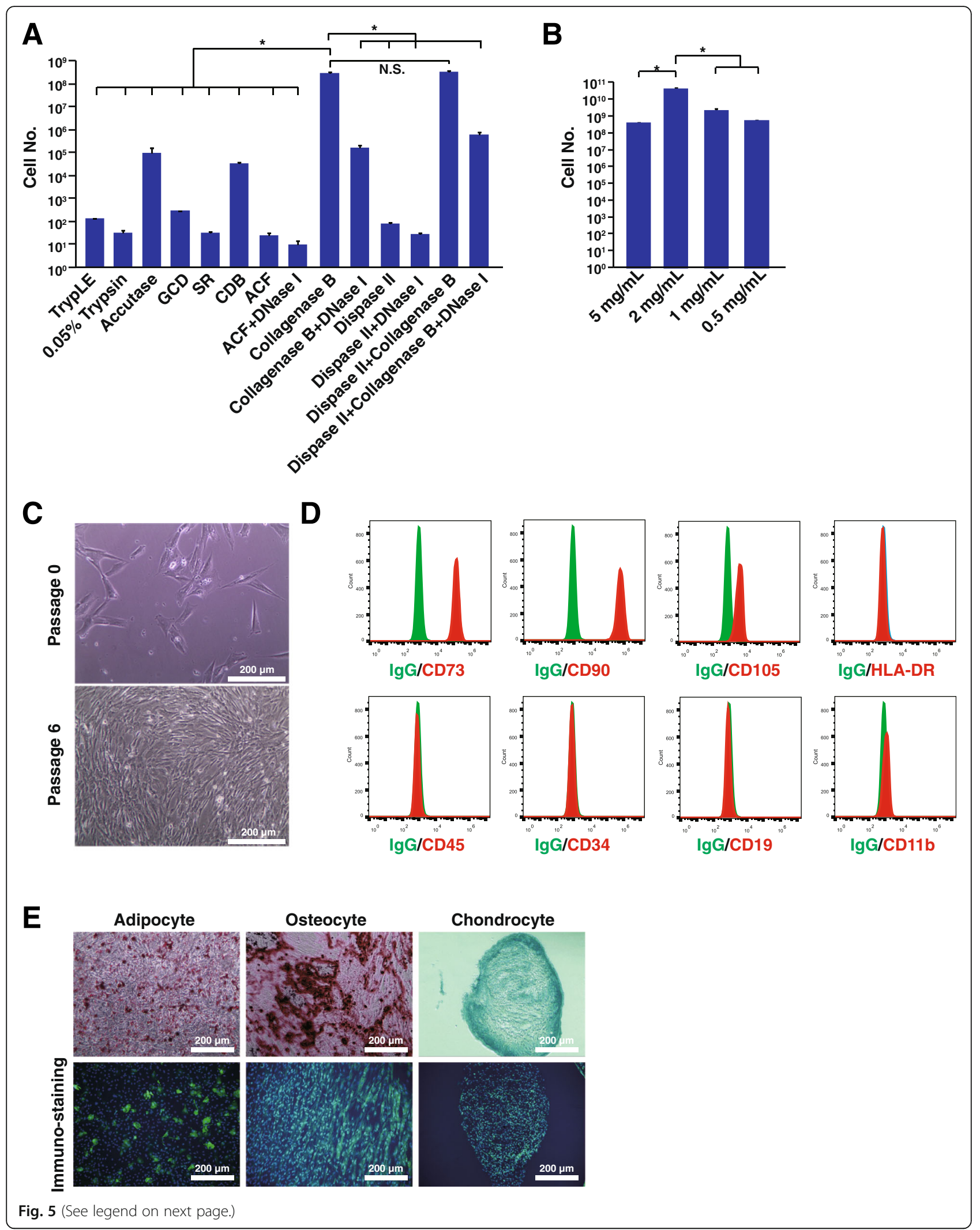


(See figure on previous page.)

Fig. 5 The NBVbe medium supports the human MSC isolation from the umbilical cords. a Cell isolation reagents comparison. Cell number was counted 30 days after the cell isolation. $\mathbf{b}$ Human MSCs were isolated with the different concentration of collagenase B. Cell number was counted 30 days after the cell isolation. $\mathbf{c}$ Human MSCs isolated from the umbilical cord, passage 0 and 6 cultured with the NBVbe medium. $\mathbf{d}$ Flow cytometry analysis of the human MSCs after isolated and cultured with the NBVbe medium. e Human MSCs were isolated and expanded with the NBVbe medium and then differentiated into adipocytes, osteocytes, and chondrocytes. Left: Oil Red O staining and anti- FABP4 immunostaining for the differentiated adipocytes; middle: Alizarin Red S staining and anti-Osteocalcin immunostaining for the differentiated osteocytes; right: Alcian blue staining and anti-Aggrecan immunostaining for the differentiated chondrocytes. Scale bar, $200 \mu \mathrm{m}$. An asterisk indicates $P<0.05$. GCD, gentle cell dissociation reagent; SR, ReLeSR ${ }^{\text {TM}}$; CDB, cell dissociation buffer, enzyme-free; ACF, animal component-free cell dissociation kit

surface marker CD73, CD90, and CD105 while negative for HLA-DAR, CD45, CD34, CD19, and CD11b (Fig. 3b). The human MSCs cultured with the NBVbe medium could form more colonies than the platelet lysate medium (Fig. 3c, d) and differentiate into adipocytes, osteocytes, and chondrocytes (Fig. 3e).

Because the MSCs cultured in the NBVbe medium were less proliferative than the PL medium, we were wondering whether further improvements could be made. RNA sequencing showed that the MSCs cultured with the NBVbe medium had a very different gene expression pattern when comparing them in culture medium containing $1 \%, 2 \%$, or $5 \%$ PL (Fig. $4 \mathrm{a}$ ). And gene clustering analysis indicated that the NBVbe medium might be more closed to the medium containing $1 \%$ platelet lysate (Fig. 4b). Indeed, there were still a large amount of differentially expressed genes between the MSCs cultured in the NBVbe medium and 5\% PL (Fig. 4c). KEGG pathway enrichment analysis for these differentially expressed genes indicated that they were mostly involved into the cell cycle and DNA replication pathways (Fig. 4d). Protein-protein interaction network analysis uncovered 15 cytokines might support the proliferation of human MSCs (Supplementary Fig. 3A, 3B). Unfortunately, these cytokines could not further promote the MSCs' proliferation in both the NB medium or the NB medium plus 3F (Supplementary Fig. 3C, 3D). Interestingly, the DNA repair pathway was also activated by the PL medium (Fig. 4d), which indicated that the 5\% PL might induce genome instability, the adverse effects alongside the fast cell proliferation. RNA sequencing also revealed that the cells cultured with 5\% PL had more alternative splicing events than those cells cultured with the NBVbe medium (Fig. 4e, f). Furthermore, the DNA exon sequencing revealed that the MSCs cultured with 5\% PL might have more SNP (single-nucleotide polymorphism) events (Fig. 4g). Thus, the NBVbe medium might introduce less DNA mutations than PL.

Thus, the full chemical-defined medium for expanding the human MSCs was developed. Then we were wondering whether it also supports the isolation of MSCs from human umbilical cord tissues. Several dissociation enzymes, reagents, and different combinations were assessed to compare their efficiency on the isolation of human MSCs. Among them, the collagenase B was the most efficient enzyme for human MSC isolation from the umbilical cords in the NBVbe medium (Fig. 5a). Concentration optimization showed that the $2 \mathrm{mg} / \mathrm{mL}$ collagenase $\mathrm{B}$ was the most efficient concentration (Fig. 5B). The isolated human MSCs were fibroblast-like cells and could be expanded with the NBVbe medium (Fig. 5c). They were positive for CD73, CD90, and CD105 expression and negative for HLA-DR, CD45, CD34, CD19, and CD11b expression (Fig. 5d). Directed differentiation assay showed that these human MSCs could be differentiated into adipocytes, osteocytes, and chondrocytes (Fig. 5e). Therefore, the NBVbe medium could be used for the isolation of human MSCs from the umbilical cords.

In conclusion, we have developed the full chemicaldefined medium for isolation and expansion of the human MSCs. The human MSCs cultured with the NBVbe medium had the self-renewal and differentiation abilities with expressing MSC markers, although the bFGF and vitamin $\mathrm{C}$ had been demonstrated as effective factors to support the human MSCs' proliferation in the conventional medium [31-33]. The NBVbe medium we developed here is the first chemical-defined medium supporting the proliferation of human MSCs with the formulation available to the public. Moreover, this would be very helpful for molecular mechanism studies of the human MSCs, including the cell identity characterization. However, the NBVbe medium was not as good as the human platelet in supporting the proliferation of human MSCs. Thus, more effects should be made to further optimize the chemical-defined medium.

\section{Supplementary information}

Supplementary information accompanies this paper at https://doi.org/10. 1186/s13287-020-01641-7.

Additional file 1: Figure S1. The top 12 expression pattern clusters analyzed by Mfuzz package in R. (EPS $14642 \mathrm{~kb}$ ) 
Additional file 2: Figure S2. KEGG pathway enrichment of cluster 3, 5, 7, 8, 9 and 11 derived from the gene expression pattern clustering analysis. (EPS $1956 \mathrm{~kb}$ )

Additional file 3: Figure S3. (A) Protein-protein interaction analysis of the genes derived from the Cell cycle and DNA replication pathway of differentially expressed genes between the cells cultured with the NBVbe medium and 5\% PL medium. (B) Protein-protein interaction analysis of the genes derived from the Cytokine and cytokine receptor interaction pathway of differentially expressed genes between the cells cultured with the NBVbe medium and 5\% PL medium. (C, D) Growth factor and chemicals screening. Human MSCs were plated onto p12 plates at $2 \times 10^{4}$ cells per well and the cell number was counted 5 days later. $3 \mathrm{~F}: \mathrm{Vc}+\mathrm{bFGF}+$ EGF; NC: negative control, NB medium; IL: interleukin; CSF2: colony stimulating factor 2; CXCL: chemokine (C-X-C motif) ligand; CCL: chemokine (CC motif) ligand. (EPS $1512 \mathrm{~kb}$ )

\section{Abbreviations}

MSCs: Mesenchymal stem cells; BSA: Bovine serum albumin;

HSCs: Hematopoietic stem cells; PL: Platelet lysate; NC: Negative control; MAPK: Mitogen-activated protein kinase; N2B27-VA: N2B27 without vitamin A; BIO: 6-Bromoindirubin-3'-oxime; OSM: Oncostatin M; Vc: Vitamin C; PDGF: Platelet-derived growth factor; bFGF: Basic fibroblast growth factor; HGF: Hepatocyte growth factor; EGF: Epidermal growth factor; IGF: Insulinlike growth factor 1; BDNF: Brain-derived neurotrophic factor; NGF: Nerve growth factor; VEGFA: Vascular endothelial growth factor A: TGFb2: Transforming growth factor beta 2

\section{Authors' contributions}

J.X. designed and supervised the project, optimized the medium composition, interpreted the data, and wrote the manuscript. W.L. conducted the cell culture experiments. J. C and W.L. collected the clinical samples. L.L. and Z.H. analyzed the data and corrected the manuscript. The authors read and approved the final manuscript.

\section{Funding}

This work was supported by Natural Science Foundation of Shenzhen (JCYJ20180305163407913, KQJSCX20180328093434771), Guangdong Provincial Science and Technology Program (No. 2019B030301009), and Medical Foundation of Guangdong (A2018308).

\section{Availability of data and materials}

All related data are available under request.

\section{Ethics approval and consent to participate}

This study was approved by the ethics committee of Shenzhen University and followed the tenants of the Declaration of Helsinki. Informed consent to participate in the study was obtained from the participants.

\section{Consent for publication}

Not applicable.

\section{Competing interests}

The authors declare that they have no competing interests.

\section{Author details}

'Guangdong Provincial Key Laboratory of Regional Immunity and Diseases, Department of Immunology, School of Medicine, Shenzhen University, Nanhai Avenue 3688, Shenzhen 518060, Guangdong, People's Republic of China. ${ }^{2}$ Department of Obstetrics, People's Hospital of Baoan, Shenzhen 518055, People's Republic of China. ${ }^{3}$ Department of Obstetrics, Women and Children Health Institute of Futian, Shenzhen 518055, People's Republic of China.

\section{Received: 9 October 2019 Revised: 3 March 2020} Accepted: 10 March 2020 Published online: 19 March 2020

\section{References}

1. Shi $Y$, et al. Immunoregulatory mechanisms of mesenchymal stem and stromal cells in inflammatory diseases. Nat Rev Nephrol. 2018;14:493-507.
2. Wang $Y$, Chen $X$, Cao W, Shi Y. Plasticity of mesenchymal stem cells in immunomodulation: pathological and therapeutic implications. Nat Immunol. 2014;15:1009-16.

3. Frenette PS, Pinho S, Lucas D, Scheiermann C. Mesenchymal stem cell: keystone of the hematopoietic stem cell niche and a stepping-stone for regenerative medicine. Annu Rev Immunol. 2013;31:285-316.

4. Parekkadan B, Milwid JM. Mesenchymal stem cells as therapeutics. Annu Rev Biomed Eng. 2010;12:87-117.

5. Uccelli A, Moretta L, Pistoia V. Mesenchymal stem cells in health and disease. Nat Rev Immunol. 2008:8:726-36.

6. Jiang $\mathrm{W}, \mathrm{Xu}$ J. Immune modulation by mesenchymal stem cells. Cell Prolif. 2020;53:e12712.

7. Kfoury $Y$, Scadden DT. Mesenchymal cell contributions to the stem cell niche. Cell Stem Cell. 2015;16:239-53.

8. Mendez-Ferrer $\mathrm{S}$, et al. Mesenchymal and haematopoietic stem cells form a unique bone marrow niche. Nature. 2010;466:829-34.

9. LV FJ, Tuan RS, Cheung KM, Leung VY. Concise review: the surface markers and identity of human mesenchymal stem cells. Stem Cells. 2014;32:1408-19.

10. Bianco P. "Mesenchymal" stem cells. Annu Rev Cell Dev Biol. 2014;30: 677-704.

11. Bieback K, et al. Human alternatives to fetal bovine serum for the expansion of mesenchymal stromal cells from bone marrow. Stem Cells. 2009;27:2331-41.

12. Kocaoemer A, Kern $\mathrm{S}$, Kluter $\mathrm{H}$, Bieback K. Human AB serum and thrombinactivated platelet-rich plasma are suitable alternatives to fetal calf serum for the expansion of mesenchymal stem cells from adipose tissue. Stem Cells. 2007; $25: 1270-8$

13. Wuchter $P$, et al. Standardization of good manufacturing practice-compliant production of bone marrow-derived human mesenchymal stromal cells for immunotherapeutic applications. Cytotherapy. 2015;17:128-39.

14. Lucarelli $E$, et al. Platelet-derived growth factors enhance proliferation of human stromal stem cells. Biomaterials. 2003;24:3095-100.

15. Xu J, et al. Additive therapeutic effects of mesenchymal stem cells and IL-37 for systemic lupus erythematosus. J Am Soc Nephrol. 2020;31:54-65.

16. Xu J, et al. Improved therapeutic consistency and efficacy of mesenchymal stem cells expanded with chemically defined medium for systemic lupus erythematosus. Cell Mol Immunol. 2020. https://doi.org/10.1038/s41423-0200364-4. Epub ahead of print.

17. Heddle NM. Cytokines in Platelet Concentrates. Hematology. 1997;2:473-84.

18. O'Neill EE, et al. Towards complete analysis of the platelet proteome. Proteomics. 2002;2:288-305.

19. Garcia A, et al. Extensive analysis of the human platelet proteome by twodimensional gel electrophoresis and mass spectrometry. Proteomics. 2004;4: 656-68.

20. Dean WL, Lee MJ, Cummins TD, Schultz DJ, Powell DW. Proteomic and functional characterisation of platelet microparticle size classes. Thromb Haemost. 2009;102:711-8.

21. Wong JW, McRedmond JP, Cagney G. Activity profiling of platelets by chemical proteomics. Proteomics. 2009:9:40-50.

22. Kinzebach S, Dietz L, Kluter H, Thierse HJ, Bieback K. Functional and differential proteomic analyses to identify platelet derived factors affecting ex vivo expansion of mesenchymal stromal cells. BMC Cell Biol. 2013;14:48.

23. Parazzi $V$, et al. Extensive characterization of platelet gel Releasate from cord blood in regenerative medicine. Cell Transplant. 2015;24:2573-84.

24. Pagel O, Walter E, Jurk K, Zahedi RP. Taking the stock of granule cargo: platelet releasate proteomics. Platelets. 2017;28:119-28.

25. Chang L, Karin M. Mammalian MAP kinase signalling cascades. Nature. 2001; 410:37-40.

26. Zhou Q, et al. Complete meiosis from embryonic stem cell-derived germ cells in vitro. Cell Stem Cell. 2016;18:330-40.

27. Ying $\mathrm{QL}$, et al. The ground state of embryonic stem cell self-renewal. Nature. 2008;453:519-23.

28. Brewer GJ, Torricelli JR, Evege EK, Price PJ. Optimized survival of hippocampal neurons in B27-supplemented Neurobasal, a new serum-free medium combination. J Neurosci Res. 1993;35:567-76.

29. Roth S, Zhang S, Chiu J, Wirth EK, Schweizer U. Development of a serumfree supplement for primary neuron culture reveals the interplay of selenium and vitamin E in neuronal survival. J Trace Elem Med Biol. 2010;24: 130(11):2693-2706.7 
30. Xu JY, et al. Generation of induced cardiospheres via reprogramming of skin fibroblasts for myocardial regeneration. Stem Cells. 2016;34(11):2693-706.

31. Ng F, et al. PDGF, TGF-beta, and FGF signaling is important for differentiation and growth of mesenchymal stem cells (MSCs): transcriptional profiling can identify markers and signaling pathways important in differentiation of MSCs into adipogenic, chondrogenic, and osteogenic lineages. Blood. 2008;112:295-307.

32. Chase LG, Lakshmipathy U, Solchaga LA, Rao MS, Vemuri MC. A novel serum-free medium for the expansion of human mesenchymal stem cells. Stem Cell Res Ther. 2010;1:8.

33. Fujisawa $\mathrm{K}$, et al. Evaluation of the effects of ascorbic acid on metabolism of human mesenchymal stem cells. Stem Cell Res Ther. 2018;9:93.

\section{Publisher's Note}

Springer Nature remains neutral with regard to jurisdictional claims in published maps and institutional affiliations.

Ready to submit your research? Choose BMC and benefit from:

- fast, convenient online submission

- thorough peer review by experienced researchers in your field

- rapid publication on acceptance

- support for research data, including large and complex data types

- gold Open Access which fosters wider collaboration and increased citations

- maximum visibility for your research: over $100 \mathrm{M}$ website views per year

At BMC, research is always in progress.

Learn more biomedcentral.com/submissions 